\title{
Composição tecidual e centesimal e teor de colesterol da carne de cordeiros terminados em confinamento com dietas contendo níveis crescentes de resíduo úmido de cervejaria
}

\author{
Tissue and centesimal composition and cholesterol of the meat of lambs feedlot with diets \\ with different levels of brewery's residue
}

\author{
Sérgio Carvalho ${ }^{*}$ Mariana Augusta Brochier ${ }^{\mathrm{I}}$
}

\section{RESUMO}

Este estudo teve como objetivo avaliar a influência de diferentes níveis de substituição do alimento concentrado por resíduo úmido de cervejaria sobre a composição tecidual, a composição centesimal e o teor de colesterol da carne de cordeiros terminados em confinamento. Foram utilizados 25 cordeiros, machos, não-castrados, da raça Texel, distribuídos aleatoriamente em cinco tratamentos compostos por níveis de substituição do alimento concentrado por resíduo úmido de cervejaria, sendo: 0\%, 25\%, 50\%, 75\% e 100\% de substituição. Foram utilizadas uma dieta composta de feno de Tifton-85 e uma mistura concentrada em uma relação volumoso: concentrado de 40:60, com base na matéria seca (MS). O alimento concentrado foi constituído por milho desintegrado, farelo de soja, mistura mineral e resíduo úmido de cervejaria, sendo que suas proporções variaram de acordo com os tratamentos. As dietas foram formuladas para serem isoprotéicas, baseados no teor de proteína bruta $(P B)$ do tratamento com maior nível de resíduo. Os cordeiros foram abatidos após um período experimental de 77 dias. Observouse, na secção entre a $9^{a}$ e a $11^{\underline{a}}$ costelas, que os pesos de osso, músculo e gordura diminuíram linearmente e a proporção de músculo aumentou linearmente com o incremento do nível de resíduo. Verificou-se aumento linear na proporção de umidade no músculo Longissimus dorsi com o aumento do resíduo úmido de cervejaria nas dietas dos cordeiros.

Palavras-chave: alimentação, composição química, ovinos, Longissimus dorsi.

\section{ABSTRACT}

The purpose of this experiment was to evaluate the influence of different levels of substitution of the concentrate by brewery's residue on the tissue composition, centesimal composition and cholesterol content in the meat of lambs finished in feedlot. Twenty-five male, non castrated Texel lambs were used, distributed in five treatments, which consisted in the levels of brewery's residue replacing concentrate, being $0 \%$, $25 \%, 50 \%, 75 \%$ and $100 \%$ of substitution. Diet's composition was Tifton-85 hay and concentrate mixture, in a relation roughage:concentrate of 40:60, on dry matter (DM). The concentrate was composed of corn ground grain, soybean meal, mineral mix and brewery's residue, and its proportion varied in accordance with the treatments. The diets were formulated to be isoproteics, based on the crude protein (CP) level of the treatment with the higher level of residue. The lambs were slaughtered after 77 days of experiment. It was observed, in the section between $9^{\text {th }}$ and $11^{\text {th }}$ ribs, that the weights of bone, muscle and fat had linearly decreased, and the proportion of muscle had linearly increased with the increase of the level of the residue. There was a linear increase in the proportion of humidity in the Longissimus dorsi muscle with the increase of the brewery's residue on the lamb's diets.

Key words: feeding, chemical composition, sheep, Longissimus dorsi.

\section{INTRODUÇÃO}

Atualmente, a ovinocultura se apresenta como uma excelente alternativa para aumento da rentabilidade das propriedades rurais, principalmente no que se refere à produção de carne de cordeiros destinados para o abate. Nesse contexto, o confinamento é um sistema alimentar que tem sido utilizado. No entanto, segundo OLIVEIRA et al. (2002), um dos grandes problemas encontrados no confinamento de ovinos tem sido os altos custos de produção, principalmente no que se refere à alimentação, o que constitui um fator determinante no aspecto financeiro.

'Programa de Pós-graduação em Gestão Tecnológica, Qualidade Ambiental. Centro Universitário Feevale, RS 239, 2755, 93352000, Novo Hamburgo, RS, Brasil. E-mail: sergiocarvalho@feevale.br. *Autor para correspondência. 
Entre as alternativas para redução dos custos de produção do sistema de confinamento, encontra-se a utilização de resíduos agroindustriais, em que o resíduo úmido de cervejaria tem grande potencial, pois este resíduo é produzido em grande volume e, além disso, não apresenta problemas com a sazonalidade de sua produção.

Com relação à carne ovina, esta é uma fonte de proteína de alto valor biológico e está presente na dieta das populações de quase todos os países, principalmente dos continentes africanos e asiáticos (ALMEIDA, 1990). Contudo, devido à atenção que o consumidor tem dado para a relação entre dieta e saúde, há uma crescente preocupação com o conteúdo de gordura e colesterol dos produtos de origem animal. Atualmente, os profissionais da saúde recomendam dietas com baixas calorias, baixo teor de gorduras saturadas e baixo colesterol a fim de reduzir o risco à saúde. Devido a estes aspectos, o conhecimento da composição tecidual, da composição centesimal e do teor de colesterol da carne ovina adquire grande importância, fazendo-se necessários estudos que identifiquem produtos mais saudáveis e que atendam a demanda dos consumidores.

De acordo com PRATA (1999), a composição centesimal da carne ovina apresenta valores médios de $75 \%$ de umidade, 19\% de proteína, $4 \%$ de gordura e $1,1 \%$ de matéria mineral, sendo que estes valores podem oscilar em função de fatores como raça, sexo, peso ao abate, ambiente, dieta e estado de acabamento do animal, resultando em variações das porcentagens de proteína, água e gordura.

ROWE et al. (1999), avaliando o efeito de diferentes sistemas de terminação na composição centesimal da carne de cordeiros, observaram maior deposição de gordura $(10,79 \%)$ no músculo Longissimus dorsi nos cordeiros que foram alimentados com dieta concentrada em comparação com aqueles alimentados com pastagem, que apresentaram 6,85\%. Já SCHÖNFELDT et al. (1993), quando compararam animais de diferentes idades, notaram que os mais jovens apresentaram maior percentual de umidade que os mais velhos. Por outro lado, MONTEIRO \& SHIMOKOMAKI (1999) não observaram aumento no teor de lipídios em cordeiros abatidos com 36 e $25 \mathrm{~kg}$.

MADRUGA et al. (2005) realizaram um estudo com o objetivo de avaliar a influência de quatro tipos de alimentos volumosos sobre os aspectos qualitativos da carne de cordeiros da raça Santa Inês, machos, não-castrados e terminados em confinamento, sendo que estes autores verificaram na perna dos cordeiros valores médios de 72,75\% para umidade, 1,11\% para cinzas, 20,34\% para proteína bruta, 6,54\% para gordura e 51,50mg $100 \mathrm{~g}^{-1}$ para colesterol. Da mesma forma, ZAPATA et al. (2001) realizaram um estudo em que avaliaram a composição centesimal e lipídica da perna de cordeiros machos, não-castrados, sendo 10 animais $1 / 2$ Somalis Brasileira $x \frac{1}{2} 2$ Crioula e 11 animais $1 / 2$ Santa Inês $\mathrm{x} 1 / 2$ Crioula, e observaram valores médios para umidade de $76,14 \%$, para proteína bruta de 19,32\%, para cinzas de $1,09 \%$, para gordura de $2,20 \%$ e para colesterol de 57,72mg $100 \mathrm{~g}^{-1}$.

O objetivo deste trabalho foi avaliar a influência de diferentes níveis de substituição do alimento concentrado por resíduo úmido de cervejaria sobre a composição tecidual, composição centesimal e teor de colesterol no músculo Longissimus dorsi de cordeiros da raça Texel, terminados em confinamento.

\section{MATERIAL E MÉTODOS}

O trabalho foi conduzido nas instalações de ovinocultura de uma propriedade rural situada no município de Capela de Santana, RS. O período experimental estendeu-se de 20 de outubro de 2005 a 04 de janeiro de 2006.

Foram utilizados 25 cordeiros, machos, nãocastrados, da raça Texel, nascidos de parto simples, desmamados aos 69 dias de idade em média. Os animais foram distribuídos aleatoriamente em cinco tratamentos, com cinco repetições cada, porém um dos animais do tratamento dois adoeceu durante o período experimental, tendo sido retirado do experimento. Os animais foram confinados em baias individuais, totalmente cobertas, com piso ripado e dimensão de $1,5 \mathrm{~m}^{2}$ por animal. Todas as baias eram providas de comedouros e bebedouros, onde foram fornecidos alimento e água para os animais.

Os tratamentos foram constituídos por diferentes níveis de substituição do alimento concentrado da dieta por resíduo úmido de cervejaria, a saber: $\mathrm{T} 1=0 \%$; $\mathrm{T} 2=25 \%$; $\mathrm{T} 3=50 \%$; $\mathrm{T} 4=75 \%$ e T5=100\% de substituição.

Após o desmame, os cordeiros foram mantidos em regime de confinamento recebendo uma dieta composta de feno de Tifton-85 e mistura concentrada em uma relação volumoso:concentrado de 40:60, com base na matéria seca (MS). O alimento concentrado foi constituído por milho desintegrado, farelo de soja, mistura mineral e resíduo úmido de cervejaria, sendo que as suas proporções variaram de acordo com os tratamentos. As dietas foram formuladas para serem isoprotéicas, baseadas no teor de proteína bruta (PB) do tratamento com maior nível de resíduo. Na tabela 1 é apresentada a proporção dos ingredientes utilizados na formulação das dietas e a composição química das dietas experimentais. 
Tabela 1 - Proporção dos ingredientes e composição química das dietas experimentais em termos de Matéria Seca (MS), Proteína Bruta (PB), Fibra em Detergente Neutro (FDN), Energia Líquida (EL), Cálcio (Ca) e Fósforo (P).

\begin{tabular}{|c|c|c|c|c|c|}
\hline & 0 & 25 & 50 & 75 & 100 \\
\hline & \multicolumn{5}{|c|}{ Proporção dos ingredientes (\%MS) } \\
\hline Feno de Tifton-85 & 40 & 40 & 40 & 40 & 40 \\
\hline Milho desintegrado & 30,42 & 22,71 & 15,01 & 7,31 & ----- \\
\hline Farelo de soja & 28,62 & 21,39 & 14,16 & 6,93 & ----- \\
\hline Resíduo de cervejaria & ----- & 15,00 & 30,00 & 45,00 & 59,33 \\
\hline \multirow[t]{2}{*}{ Calcário calcítico } & 0,96 & 0,90 & 0,83 & 0,76 & 0,67 \\
\hline & \multicolumn{5}{|c|}{ Composição química das dietas (\%MS) } \\
\hline MS & 84,15 & 74,34 & 64,52 & 54,70 & 45,32 \\
\hline PB & 17,52 & 17,52 & 17,52 & 17,52 & 17,52 \\
\hline FDN & 29,42 & 36,11 & 42,80 & 49,49 & 54,63 \\
\hline EL (Mcal kg-1) & 1,55 & 1,49 & 1,42 & 1,35 & 1,29 \\
\hline $\mathrm{Ca}$ & 0,55 & 0,55 & 0,55 & 0,55 & 0,55 \\
\hline $\mathrm{P}$ & 0,36 & 0,37 & 0,38 & 0,39 & 0,40 \\
\hline
\end{tabular}

O alimento foi fornecido, ad libitum, duas vezes ao dia, sendo os horários de arraçoamento às 7h30min e 17h30min. A quantidade oferecida foi ajustada em função da sobra observada diariamente, sendo que esta deveria ser de $15 \%$ da quantidade oferecida no dia anterior, de modo a garantir o consumo voluntário máximo dos animais. Nesse sentido, foram realizadas pesagens diárias das sobras e do alimento que seria oferecido pela manhã e pela tarde, para cada animal.

O período experimental foi precedido de um período de 14 dias para adaptação dos animais às instalações, à alimentação e ao manejo. O ensaio de alimentação iniciou após a fase de adaptação, estendendo-se por um período de 77 dias. Os cordeiros foram pesados no início e no final da fase experimental, após jejum de sólidos e líquidos de 12 horas, sendo que para um melhor acompanhamento do desempenho foram realizadas pesagens intermediárias a cada 14 dias. A última pesagem foi realizada com um intervalo de 21 dias.

As medidas de controle sanitário foram executadas no início do período de adaptação, tendo sido realizado controle endoparasitário e vacinação contra Carbúnculo Sintomático, Gangrena Gasosa e Enterotoxemia. Durante o período experimental, quando necessário, repetiu-se o controle endoparasitário.

O abate ocorreu após um jejum de sólidos e líquidos com duração de 12 horas. Após cada abate, a carcaça foi pesada individualmente e, em seguida, foi resfriada por 18 horas em câmara frigorífica, a uma temperatura de $1^{\circ} \mathrm{C}$.

Para determinação da composição tecidual, foi retirada uma amostra entre a 9ª e a 11ª costelas (seção
$\mathrm{HH}$ ), conforme procedimento descrito em HANKINS \& HOWE (1946). Então estas amostras foram identificadas, acondicionadas em saco plástico e congeladas para posterior análise. Depois de descongeladas, as amostras foram pesadas e em seguida procedeu-se a separação física de osso, músculo e gordura. Cada um dos componentes teciduais foi pesado e então foi calculada a percentagem em relação à amostra total. Feito isso, o músculo Longissimus dorsi foi separado para determinação da composição centesimal. Assim, foram determinados os teores de matéria seca, matéria mineral, proteína bruta e extrato etéreo, conforme procedimentos descritos em CARVALHO \& JONG (2002). Foram também coletadas amostras do músculo Longissimus dorsi nas quais foram determinados os teores de colesterol, conforme CARVALHO \& JONG (2002).

O delineamento experimental utilizado foi o inteiramente casualizado com cinco tratamentos e cinco repetições, sendo cada cordeiro considerado uma unidade experimental. Os dados foram submetidos à análise de regressão, com auxílio do pacote estatístico SAS (SAS, 2001). Os modelos foram selecionados com base nos coeficientes de determinação e na significância dos coeficientes de regressão, adotando-se o nível de $5 \%$ de probabilidade, utilizando-se o teste F.

\section{RESULTADOS E DISCUSSÃO}

Na tabela 2 são apresentados os valores médios para o peso da amostra, pesos e proporções de osso, músculo e gordura da secção entre a $9^{\underline{a}}$ e a $11^{\text {a }}$ costelas (seção HH), em função dos níveis de substituição do alimento concentrado por resíduo 
Tabela 2 - Valores médios para peso vivo ao abate (PVA), peso de carcaça fria (PCF), peso da amostra (PAmostra), pesos e proporções de osso, músculo e gordura da secção entre a $9^{\underline{a}}$ e a $11^{\underline{a}}$ costelas, em função dos níveis de substituição do alimento concentrado por resíduo úmido de cervejaria.

\begin{tabular}{|c|c|c|c|c|c|c|c|}
\hline \multirow{2}{*}{ Itens } & \multicolumn{5}{|c|}{ 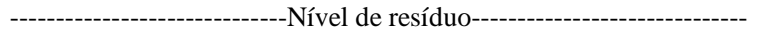 } & \multirow{2}{*}{ Equação de Regressão } & \multirow{2}{*}{ CV (\%) } \\
\hline & 0 & 25 & 50 & 75 & 100 & & \\
\hline PVA (kg) & 28,00 & 28,20 & 26,80 & 28,48 & 22,12 & $?=26,66$ & 20,71 \\
\hline PCF (kg) & 12,98 & 13,22 & 11,98 & 12,42 & 8,92 & 1 & 23,29 \\
\hline PAmostra & 181,43 & 167,48 & 153,81 & 143,80 & 96,26 & 2 & 28,29 \\
\hline Osso (g) & 55,84 & 43,67 & 45,12 & 38,18 & 24,09 & 3 & 38,05 \\
\hline Músculo (g) & 95,43 & 100,15 & 88,00 & 83,42 & 60,72 & 4 & 27,66 \\
\hline Gordura (g) & 30,16 & 23,65 & 20,69 & 22,20 & 11,46 & 5 & 42,48 \\
\hline Osso (\%) & 30,54 & 25,44 & 29,06 & 26,66 & 24,80 & $\hat{Y}=27,38$ & 20,30 \\
\hline Músculo (\%) & 53,21 & 60,10 & 57,39 & 58,48 & 63,11 & 6 & 7,78 \\
\hline Gordura (\%) & 16,25 & 14,45 & 13,55 & 14,86 & 12,09 & $\hat{Y}=14,23$ & 28,94 \\
\hline
\end{tabular}

1. $\hat{\mathrm{Y}}=13,65020-0,03531^{* *} \mathrm{RES}, \mathrm{R}^{2}=0,18$;

2. $\hat{Y}=187,40073-0,77646 * *$ RES, $R^{2}=0,32$;

3. $\hat{Y}=55,57189-0,27993 * * R E S, R^{2}=0,31$;

4. $\hat{\mathrm{Y}}=102,26505-0,33948 * * * R E S, \mathrm{R}^{2}=0,22$;

5. $\hat{Y}=29,56380-0,15705^{* *}$ RES, $R^{2}=0,29$;

6. $\hat{Y}=54,53219+0,07561^{* *}$ RES, $R^{2}=0,28$.

** e *** significativo a 5 e $1 \%$ de probabilidade, respectivamente, pelo teste $\mathrm{F}$.

RES = Nível de resíduo úmido de cervejaria da dieta.

úmido de cervejaria. Deve-se enfatizar que no presente experimento optou-se por determinar a composição tecidual da secção entre a 9a e a 11aㅡ costelas, pois a amostra do músculo Longissimus dorsi nesta secção foi a utilizada para determinação da composição centesimal. Além disso, vários autores vêm utilizando partes da carcaça como sendo representativo da mesma em termos de composição tecidual, pois, segundo SOUZA (1993), a dissecação de toda a carcaça ou de metade apenas só se justifica em casos especiais, por ser onerosa, trabalhosa e lenta. Assim, salienta-se que a determinação da composição tecidual da carcaça de bovinos por intermédio de um método indireto já é utilizada há bastante tempo, conforme demonstrado por HANKINS \& HOWE (1946), os quais definiram uma metodologia para a obtenção de uma amostra compreendendo entre a 9a e a 11 $1^{\mathrm{a}}$ costelas (seção HH). Portanto, neste estudo, adotou-se a seção HH para determinação da composição tecidual. Contudo, uma vez que a estimativa da composição tecidual a partir desta secção foi desenvolvida para bovinos, enfatizase que os resultados obtidos no presente estudo são apenas para esta secção e não representam uma estimativa da composição da carcaça dos cordeiros como um todo.

A análise de regressão indicou que não houve efeito significativo do nível de substituição do alimento concentrado por resíduo úmido de cervejaria sobre o peso vivo dos cordeiros no momento do abate. Por outro lado, os pesos de osso, músculo e gordura diminuíram linearmente com o aumento do nível de substituição. Este resultado pode ser explicado pela redução verificada no peso de carcaça fria obtida após o abate dos animais, o que levou à redução do peso da secção entre a 9a e a $11^{\mathrm{a}}$ - costelas e, conseqüentemente, do peso dos tecidos constituintes.

Quando a composição tecidual da secção utilizada foi avaliada em termos relativos, observou-se efeito linear crescente sobre a porcentagem de músculo à medida que se elevou o nível de inclusão de resíduo nas rações, sendo que as porcentagens de osso e gordura não foram influenciadas estatisticamente.

Os valores médios obtidos de 27,38\%, $58,46 \%$ e $14,23 \%$ para osso, músculo e gordura, respectivamente, estão próximos aos obtidos por CARVALHO (1998), o qual verificou em cordeiros cruza Texel x Ideal, machos, não-castrados, terminados em confinamento e abatidos com 100 dias de idade, com peso vivo médio de $27,91 \mathrm{~kg}$, valores médios de 22,04\% para osso, 62,70\% para músculo e 16,40\% para gordura, na carcaça dos animais. Resultados semelhantes aos deste estudo foram também obtidos por ROSA et al. (2002), os quais realizaram um experimento com o objetivo de avaliar a composição tecidual da carcaça e de seus cortes em cordeiros da raça Texel e observaram em machos não-castrados e abatidos com 33kg de peso vivo um valor médio de 59,28\% de músculo na carcaça dos animais. Contudo, os valores obtidos por estes autores para as porcentagens de osso e gordura foram de $18,04 \%$ e 22,10\%, respectivamente, resultados esses

Ciência Rural, v.38, n.7, out, 2008. 
que diferem dos obtidos no presente experimento. Cabe salientar que as diferenças observadas podem ser conseqüência de diferentes progênies utilizadas nos diferentes estudos que podem não expressar valores médios da raça em questão.

Na tabela 3 é apresentada a composição centesimal e o teor de colesterol do músculo Longissimus dorsi em função dos níveis de substituição do alimento concentrado por resíduo de cervejaria. Houve variação linear decrescente para os valores de matéria seca e variação linear crescente para os teores de umidade, o que é explicado pelo aumento da proporção de músculo e pela redução numérica da gordura. Para os teores de proteína, extrato etéreo e cinzas, não foram verificadas diferenças estatisticamente significativas entre os diferentes tratamentos.

De acordo com PRATA (1999), a composição centesimal da carne ovina apresenta valores médios de $75 \%$ de umidade, 19\% de proteína, $4 \%$ de extrato etéreo e $1,1 \%$ de matéria mineral. Os valores de composição centesimal encontrados neste estudo estão de acordo com estes, com exceção do extrato etéreo que foi inferior, fato atribuído à variação desta fração em função do peso de abate e do músculo utilizado para a análise.

Os valores obtidos neste trabalho estão de acordo com os encontrados por ZAPATA et al. (2001), que, ao estudarem a composição centesimal de borregos machos inteiros e mestiços das raças Crioula, Somalis Brasileira e Santa Inês, obtiveram valores médios de 76,15\% para umidade, 19,30\% para proteína bruta e $1,09 \%$ para cinzas; diferindo apenas quanto ao resultado de extrato etéreo, que se mostrou mais elevado (2,17\%) do que no presente estudo. BRITO et al. (2005), trabalhando com 36 cordeiros das raças Texel e Santa Inês confinados para avaliação de características de carcaça e composição centesimal da carne, também corroboram os resultados obtidos no presente estudo, sendo que estes autores observaram valores médios para umidade de 77,07\% e 76,75\%, para proteína bruta de $19,80 \%$ e 20,21\%, para cinzas de $1,04 \%$ e $1,07 \%$ e para extrato etéreo de $2,08 \%$ e $1,97 \%$, respectivamente, para cordeiros, machos, nãocastrados das raças Texel e Santa Inês.

Avaliando a composição centesimal no músculo Longissimus dorsi de cordeiros mestiços Texel $\mathrm{x}$ Corriedale, criados em regime de pasto e abatidos aos 270 dias de idade, MONTEIRO et al. (2001) encontraram valores próximos aos deste experimento para os teores de umidade (73,8\%) e matéria mineral (1,0\%), entretanto, para o teor de proteína (22,0\%) e gordura $(3,2 \%)$, os valores observados por estes autores foram superiores aos do presente estudo.

Com relação aos valores obtidos para colesterol, verifica-se que os mesmos não foram influenciados significativamente pelas dietas $(\mathrm{P}>0,05)$, sendo o valor médio obtido de $186,51 \mathrm{mg}^{100 \mathrm{~g}^{-1} \text { de }}$ amostra. O resultado observado é superior ao obtido por MADRUGA et al. (2005), que verificaram valores médios de 51,50mg $100 \mathrm{~g}^{-1}$ de amostra da perna de cordeiros Santa Inês. É superior também aos valores observados por PEREZ et al. (2002), os quais obtiveram um valor médio de $71,50 \mathrm{mg}^{100 \mathrm{~g}^{-1}}$ para colesterol no músculo Longissimus dorsi de cordeiros das raças Bergamácia e Santa Inês. Vale salientar que estes cordeiros apresentaram um peso vivo ao abate de $25 \mathrm{~kg}$, valor este próximo à média do presente estudo, que foi de $26,66 \mathrm{~kg}$. Os resultados superiores obtidos no presente estudo para os teores de colesterol quando comparados com a literatura podem ser explicados pela elevada proporção de alimento concentrado utilizado

Tabela 3 - Valores médios, em \%, para matéria seca, umidade, proteína bruta, extrato etéreo, cinzas e colesterol (mg 100g ${ }^{-1}$ ) do músculo Longissimus dorsi em função dos níveis de substituição do alimento concentrado por resíduo úmido de cervejaria.

\begin{tabular}{|c|c|c|c|c|c|c|c|}
\hline \multirow{2}{*}{ Itens } & & & el de resíc & & ----- & \multirow{2}{*}{ Equação de regressão } & \multirow{2}{*}{ CV (\%) } \\
\hline & 0 & 25 & 50 & 75 & 100 & & \\
\hline Matéria seca & 25,57 & 24,85 & 25,33 & 23,79 & 24,03 & 1 & 5,02 \\
\hline Umidade & 74,43 & 75,15 & 74,66 & 76,21 & 75,97 & 2 & 1,64 \\
\hline Proteína bruta & 18,89 & 19,31 & 19,31 & 19,06 & 19,73 & $\hat{\mathrm{Y}}=19,26$ & 7,57 \\
\hline Extrato etéreo & 1,20 & 1,45 & 0,72 & 1,25 & 0,87 & $\hat{Y}=1,08$ & 44,30 \\
\hline Cinzas & 1,10 & 1,07 & 1,09 & 1,09 & 1,19 & $\hat{Y}=1,11$ & 11,71 \\
\hline Colesterol & 220,90 & 145,32 & 171,12 & 184,52 & 210,67 & $\hat{Y}=186,51$ & 22,81 \\
\hline
\end{tabular}

1. $\hat{\mathrm{Y}}=25,56780-0,01681^{* *} \mathrm{RES}, \mathrm{R}^{2}=0,20$

2. $\hat{\mathrm{Y}}=74,43220+0,01681 * * \mathrm{RES}, \mathrm{R}^{2}=0,20$

** significativo a $5 \%$ de probabilidade pelo teste $\mathrm{F}$.

RES = Nível de resíduo úmido de cervejaria da dieta. 
na alimentação dos cordeiros no presente estudo, que foi de $60 \%$ da matéria seca total da dieta.

Do ponto de vista prático, os resultados apresentados poderão subsidiar a produção de carne ovina no que se refere aos aspectos qualitativos, podendo contribuir para orientação da produção de um produto que atenta a demanda do mercado consumidor, principalmente relacionado às proporções de músculo e gordura e ao teor de colesterol das carcaças de cordeiros terminados em confinamento.

\section{CONCLUSÕES}

O aumento do nível de substituição do alimento concentrado por resíduo úmido de cervejaria na alimentação de cordeiros da raça Texel confinados na fase de terminação promove redução da densidade energética das dietas, o que reduz linearmente o peso da amostra obtida entre a $9^{\underline{a}}$ e a $11^{\underline{a}}$ costelas, ocasionando redução linear dos pesos de osso, músculo e gordura e aumento linear da proporção de músculo desta amostra. Como conseqüência do aumento da proporção de músculo, há um crescimento linear na proporção de umidade no músculo Longissimus dorsi dos cordeiros à medida que aumenta o nível de resíduo úmido de cervejaria nas dietas.

\section{REFERÊNCIAS}

ALMEIDA, M.M.M. Estudo da composição química das carnes de caprinos e ovinos criados no sertão do Ceará. 1990. 78f. Dissertação (Mestrado em Tecnologia de Alimentos) - Curso de Pós-graduação em Tecnologia de Alimentos, Universidade Federal do Ceará.

BRITO, R.A.M. et al. Características da carcaça e composição centesimal da carne de borregos de dois genótipos criados em confinamento. In: CONGRESSO DE PESQUISA, ENSINO E EXTENSÃO, 2., 2005, Goiânia, GO. Anais... Goiânia: Universidade Federal de Goiânia, 2005.

CARVALHO, H.H.; JONG, E.V. Alimentos - métodos físicos e químicos de análise. Porto Alegre: UFRGS, 2002. 180p.

CARVALHO, S. Desempenho, composição corporal e exigências nutricionais de cordeiros machos inteiros, machos castrados e fêmeas alimentados em sistema de confinamento. 1998. 116f. Dissertação (Mestrado em Zootecnia) - Curso de Pós-graduação em Zootecnia, Universidade Federal de Santa Maria.
HANKINS, O.G.; HOWE, P.E. Estimation of the composition of beef carcasses and cuts. Washington: USDA, 1946. 20p. (Tecnical Bulletin USDA, 926).

MADRUGA, M.S. et al. Qualidade da carne de cordeiros Santa Inês terminados em diferentes dietas. Revista Brasileira de Zootecnia, v.34, n.1, p.309-315, 2005.

MONTEIRO, E.M.; SHOMOKOMAKI, M. Influência do genótipo nos lipídios totais e na fração insaponificável da carne de cordeiros. Ciência Rural, v.29, n.3, p.545-548, 1999.

MONTEIRO, E.M. et al. Avaliação de parâmetros de qualidade da carcaça e da carne de ovinos. In: CONGRESSO BRASILEIRO DE CIÊNCIA E TECNOLOGIA DE CARNES, 2001, São Pedro, SP. Anais... São Pedro: CTC/ITAL, 2001. p.98-99.

OLIVEIRA, M.V.M. et al. Avaliação da composição dos cortes comerciais, componentes corporais e órgãos internos de cordeiros confinados e alimentados com dejetos de suínos. Revista Brasileira de Zootecnia, v.31, n.3, p.1459-1468, 2002.

PEREZ, J.R.O. et al. Efeito do peso ao abate de cordeiros Santa Inês e Bergamácia sobre o perfil de ácidos graxos, colesterol e propriedades químicas. Revista Ciência e Tecnologia Alimentar. v.22, n.1, p.11-18, 2002.

PRATA, L.F. Higiene e inspeção de carnes, pescado e derivados. Jaboticabal: FUNEP, 1999. 217p.

ROSA, G.T. et al. Composição tecidual da carcaça e de seus cortes e crescimento alométrico do osso, músculo e gordura da carcaça de cordeiros da raça Texel. Acta Scientiarum, v.24, n.4, p.1107-1111, 2002.

ROWE, A. et al. Muscle composition and fatty acid profile in lambs fattened in dry lot or pasture. Meat Science, v.51, n.3, p.283-288, 1999.

SAS INSTITUTE. Statistical analysis system user's guide. Versão 6, 4.ed. Cary, 2001. 846p.

SCHÖNFELDT, H.C. et al. Cooking and juiciness-related quality characteristics of goat and sheep and meat. Meat Science, v.34, p.381-394, 1993.

SOUZA, O.R.C. Rendimento de carcaça, composição regional e física da paleta e quarto em cordeiros Romney Marsh abatidos aos 90 e 180 dias de idade. 1993. $102 \mathrm{f}$. Dissertação (Mestrado em Zootecnia) - Curso de Pós-graduação em Zootecnia, Universidade Federal de Pelotas.

ZAPATA, J.F.F. et al. Composição centesimal e lipídica da carne de ovinos do nordeste brasileiro. Ciência Rural, v.31, n.4, p.691-695, 2001. 